\title{
One stage endovascular treatment of multiple intracranial aneurysms
}
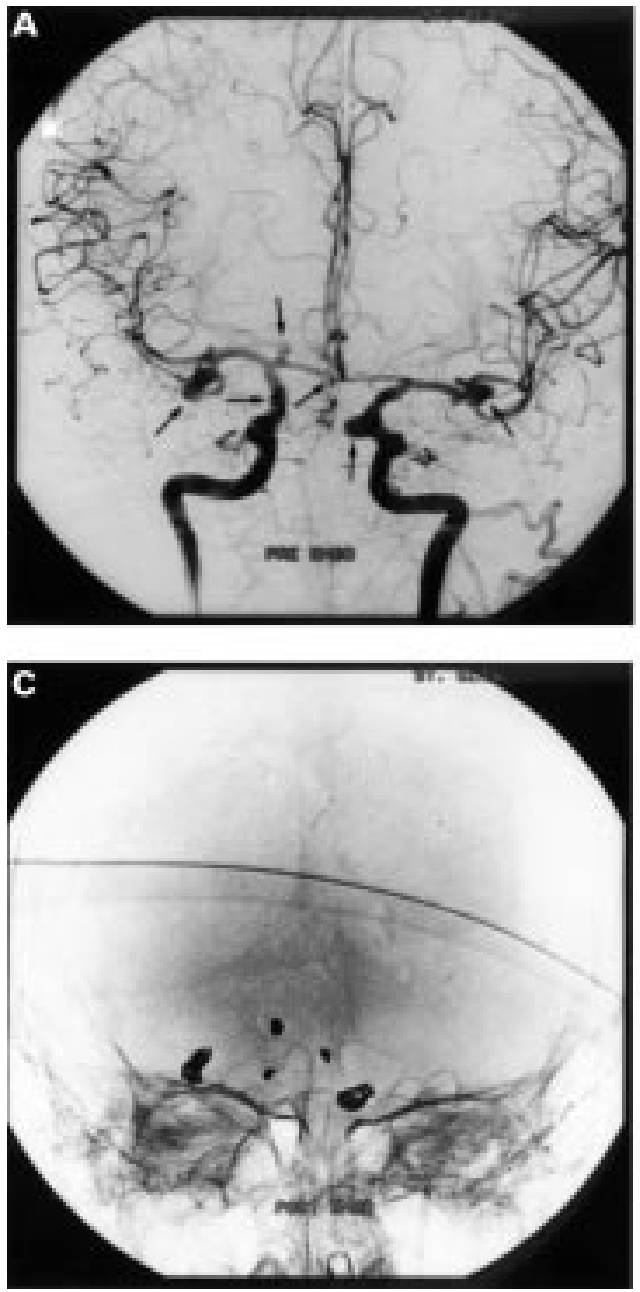

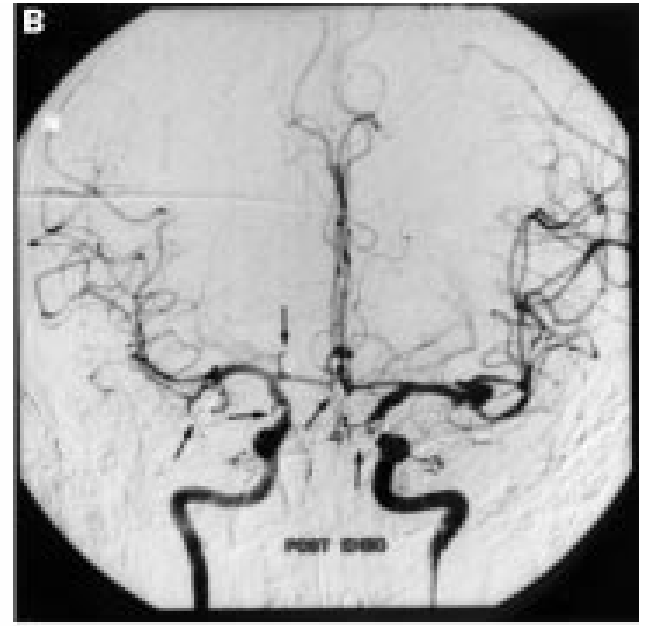

A 69 year old woman presented with an acute severe headache. At neurological examination a slight stiffness of the neck was found without further abnormalities. Brain CT showed diffuse blood in the basal cisterns and sylvian fissures, indicative of a subarachnoid haemorrhage. Angiography disclosed six aneurysms located at different sites in the anterior cerebral circulation (figure A). Neither from CT and angiography, nor from additional MRI, was it clear which aneurysm had ruptured. During the next few days the patient's consciousness deteriorated as a result of a developing hydrocephalus, necessitating temporary lumbar drainage. Eleven days after the bleeding an endovascular procedure was performed. Five of the six aneurysms were treated succesfully with electrolytically detachable coils in one session that lasted three hours (figures B and C). One of the six aneurysms (left middle cerebral artery) could not be coiled due to the wide aneurysmal neck. After treatment the patient was in good clinical condition without neurological deficit. An operation for the sixth aneurysm is planned in the future.

WILLEM JAN VAN ROOIJ

Department of Radiology, St Elisabeth Hospital, PO Box 90151, Tilburg, 5000 LC,

The Netherlands

CEES C TIJSSEN Department of Neurology, St Elisabeth Hospital, PO Box 90151, Tilburg, 5000 LC,

The Netherlands

Correspondence to: Dr CC Tijssen, Department of Neurology, St Elisabeth Hospital, PO Box 90151, Tilburg 5000 LC, The Netherlands. Telephone 003113 5392554; fax 0031135422538 